\title{
A nutrição clínica ampliada e a humanização da relação nutricionista-paciente: contribuições para reflexão
}

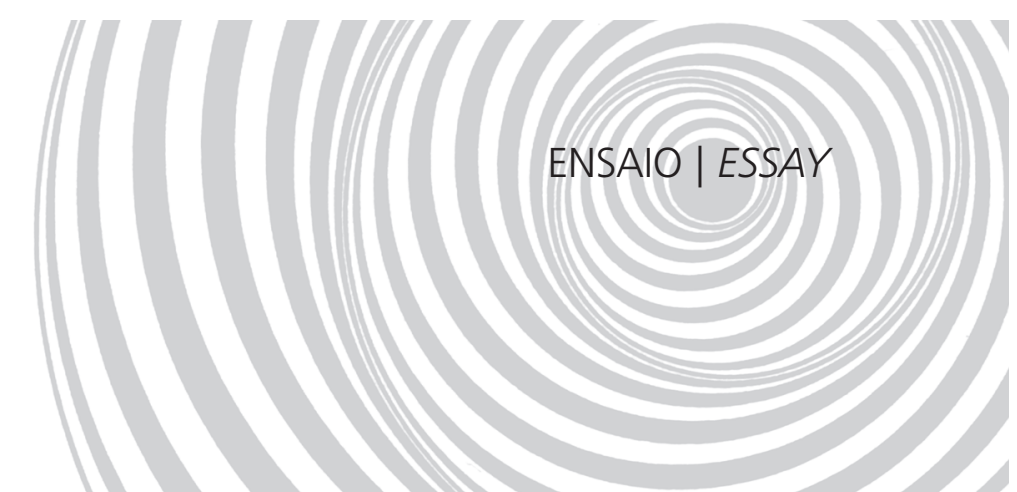

\section{The extended nutritional clinic and humanization \\ of patient-nutritionist relationship: contribution to reflection}

Franklin DEMÉTRIO'

Janaína Braga de PAIVA

Ana América Gonçalves FRÓES ${ }^{3}$

Maria do Carmo Soares de FREITAS ${ }^{4}$

Lígia Amparo da Silva SANTOS ${ }^{4}$

A concepção da clínica nutricional ampliada é uma temática nova para o campo da nutrição, sobretudo da nutrição clínica. Diante do processo de reformulações nos cenários de práticas em saúde no âmbito do Sistema Único de Saúde, esse tema instiga substancial interesse na produção científica, na formação e na prática clínica do nutricionista com a aplicação de competências comunicacionais e a ampliação do olhar técnico-nutricional perante o processo saúde-doença-cuidado, que podem contribuir para a reconfiguração da relação nutricionista-paciente a fim de ampliar sua humanização. Este ensaio mostra como a concepção de nutrição clínica ampliada pode contribuir para refletir sobre a ampliação da humanização da relação nutricionista-paciente no âmbito dos serviços de saúde. O ensaio é delineado em duas partes: o ponto de partida e o ponto de continuação. No ponto de partida, analisam-se publicações oficiais sobre a conformação sócio-histórica do modelo biomédico e sua repercussão na prática clínica. No ponto de continuação, observa-se a clínica nutricional como prática social e utiliza-se a concepção da clínica ampliada para discutir as possibilidades de reestruturar a nutrição clínica e ampliar seus saberes e suas técnicas para além de um modelo biomédico restrito e restritivo. Por fim, discute-se a nutrição clínica ampliada como possibilidade para repensar a relação nutricionista-paciente e propor, nesse sentido, sua humanização, a incorporação de conteúdos não biomédicos, a valorização da sabedoria prática e da escuta, a articulação de saberes e a exploração da dimensão dialógica no exercício legítimo da nutrição clínica na contemporaneidade.

Termos de indexação: Competência clínica. Humanização da assistência. Interdisciplinaridade. Nutricionista. Relação profissional-paciente.

1 Universidade Federal do Recôncavo da Bahia, Centro de Ciências da Saúde. Av. Carlos Amaral, no 1015, Cajueiro, 44570-000, Santo Antônio de Jesus, BA, Brasil. Correspondência para/Correspondence to: F. DEMÉTRIO. E-mails: <fdemetrio@ufrb.edu.br>; <franklindemetrio@yahoo.com.br>.

2 Universidade Federal da Bahia, Escola da Nutrição, Núcleo de Estudos e Pesquisas em Alimentação e Cultura. Salvador, BA, Brasil.

${ }^{3}$ Hospital Geral do Estado. Salvador, BA, Brasil.

${ }^{4}$ Universidade Federal da Bahia, Escola de Nutrição, Departamento de Ciência da Nutrição. Salvador, BA, Brasil. 


\section{A B S T R A C T}

The extended clinical nutrition conception is a new theme for the field of nutrition, especially clinical nutrition. Given the process of reformulation of the health practice scenarios within the Unified Healthcare System, this theme instigates a substantial interest in scientific production, in the formation and clinical practice of the dietician with the use of communication competencies and the magnification of the technical and nutritional look on the process health-disease-care, which may contribute to the reconfiguration of the relationship dieticianpatient with the purpose of amplifying its humanization. This trial shows how the conception of an extended clinical nutrition can contribute for the reflection on broadening the humanization of the relationship dieticianpatient in health services. The trial is designed in two parts: the starting point and the continuation point. At the starting point, official publications on the social, historical and political conformations of the biomedical model and its repercussion on the clinical practice are analyzed. At the continuation point, nutritional clinic is observed as a social practice and the extended clinical conception is used for discussing the possibilities of restructuring clinical nutrition and broadening its knowledge and techniques beyond a restricted and restrictive biomedical model. Finally, extended clinical nutrition is discussed, with the possibility of rethinking the relationship dietician-patient and proposing, in this sense, its humanization, the incorporation of non-biomedical contents, valuing practical knowledge and listening skills, the organization of knowledge and exploration of dialogue in the current practice of clinical nutrition.

Indexing terms: Clinical competence. Humanization of assistance. Interdisciplinary. Nutritionist. Profissionalpatient-relations.

\section{N T R O D U Ç Ã O}

Nas duas últimas décadas, tem-se observado grande número de publicações dedicadas à relação médico-paciente. O modelo tradicional que caracteriza essa relação tem sido descrito por

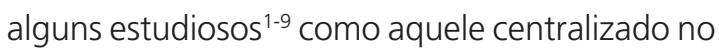
médico, na doença e na medicalização, pautando-se em uma relação que tende a ser mais autoritária, na qual o paciente e suas necessidades têm papel passivo e o médico passa a ser o detentor de toda expertise e conhecimento. Essa forma de relação baseia-se no modelo biomédico de doença - que define o cuidado médico como tratamento dos sinais e sintomas físicos em termos quantificáveis -, no qual a cura é definida por indicadores médicos objetivos ${ }^{1,2,6-9}$. Esse modus operandi em saúde, que negligencia outras contextualizações dos elementos semiológicos do processo saúde-doença-cuidado, confere desvantagem para o setor e seus usuários ${ }^{3,4}$.

Ao contrário do que se observa para a área médica, são poucos os estudos teóricos e empíricos no campo da nutrição voltados para o debate sobre a relação nutricionista-paciente na prática clínica. Entretanto, as publicações identificadas na literatura específica sinalizam a influência epistemológica da biomedicina na constituição do mo- delo vigente de relação nutricionista-paciente no cuidado clínico-nutricional na contemporaneida$\mathrm{de}^{10-14}$.

A complexidade inerente ao sistema de saúde e os progressos da medicina e nutrição têm suscitado discussões acerca da relação profissional de saúde-paciente na prática clínica ${ }^{10-15}$. Por um lado, não se deve desprezar a relevância de tais progressos para o campo da saúde; por outro, constata-se que a dimensão humana, vivencial e psicossociocultural da doença bem como os padrões e as variabilidades na comunicação verbal e não verbal precisam ser considerados no processo relacional entre o profissional da saúde e os usuários ${ }^{11,15}$. Assim, o estabelecimento de relações de confiança, respeito e reciprocidade entre nutricionista e paciente deve permear as práticas de atenção à nutrição e à saúde no intuito de ampliar a sua humanização e o vínculo terapêutico.

No contexto da política de humanização das práticas em saúde, a aplicação de tecnologias do cuidado humanizado ainda esbarra em uma cultura técnica que carece de revisão sobre os marcos do poder, da verticalização das relações e da promoção de um ambiente mais favorável à criatividade e ao acolhimento ${ }^{15-17}$. É nesse contexto que a concepção de clínica ampliada, apresentada por 
Campos \& Amaral $^{3}$, Campos $^{4}$ e Cunha ${ }^{17}$, propõe-se à tarefa de (re)pensar mecanismos que reconfigurem a relação singular profissional de saúde-usuário e de sugerir uma análise crítico-reflexiva sobre os modelos biomédico e hospitalocêntrico, que têm sustentado epistemologicamente a clínica contemporânea.

Nesse sentido, discute-se a possibilidade de ampliar a clínica nutricional para uma inovação da prática profissional em nutrição clínica não mais pensada somente com base em um a priori individual, mas na perspectiva da dialética entre sujeitos, perspectiva singular e coletividade: chamamento provocado pelos usuários dos serviços de saúde e de nutrição a um alargamento do olhar técnico-nutricional, da escuta e dos modos de trabalhar com as demandas e expectativas.

No presente ensaio, focaliza-se como a concepção de nutrição clínica ampliada pode contribuir para uma reflexão sobre a ampliação da humanização da relação nutricionista-paciente no âmbito dos serviços de saúde. Pretende-se abarcar alguns elementos dessa concepção a fim de sugerir caminhos para reformulação do modelo de clínica nutricional vigente, podendo estender-se à reflexão de outros profissionais de saúde sobre suas práticas e competência relacional com o paciente. Assim, o ensaio é delineado em duas partes, a saber: ponto de partida e ponto de continuação. No ponto de partida, reúnem-se alguns apontamentos que abrangem a conjuntura sócio-histórica conformadora do modelo biomédico por meio da trajetória de construção da medicina social e da clínica, para demonstrar que o movimento contemporâneo tem suas raízes em séculos passados, e chega-se ao Relatório Flexner, com suas consequências para a prática clínica. No ponto de continuação, resgatam-se alguns aspectos históricos do surgimento do nutricionista e da nutrição clínica no Brasil e se discute em que sentido a concepção da nutrição clínica ampliada pode contribuir para dilatar a visão humanística na prática clínica nutricional.

Para tanto, tomou-se como constructo central um repertório de publicações de teóricos do campo da saúde coletiva, filosofia, nutrição e antropologia da alimentação, que sustenta o arcabouço argumentativo necessário para incitar essa reflexão, a saber: Caprara \& Franco', Caprara \& Rodrigues $^{2}$, Campos \& Amaral $^{3}$, Campos ${ }^{4}$, Castiel \& Diaz ${ }^{9}$, Deslandes \& Mitre ${ }^{16}$, Cunha $^{17}$, Ayres $^{18}$, Foucault ${ }^{19-21}$, Luz ${ }^{6,8,22}$, Onfray' ${ }^{23}$, Schraiber $^{24}$, Bosi $^{14,25}$, Freitas ${ }^{26}$, Freitas et al. 10,11,27, Santos et al. ${ }^{28}$, Santos ${ }^{29-30}$, Diez-Garcia ${ }^{31}$, Boog ${ }^{32}$, Rodrigues et al. ${ }^{33}$, Rodrigues \& Boog ${ }^{34}$, Scagliusi et al. ${ }^{35}$, Alvarenga \& Scagliusi ${ }^{36}$, Vasconcelos ${ }^{37}$, Canesqui $^{38}$, Fischler ${ }^{39}$, Poulain \& Proença ${ }^{40}$, dentre outros que orientam esses campos de estudos ou campos científicos correlatos.

\section{Ponto de partida}

\section{Da conformação do modelo biomédico, da medicina social e do hospital ao relatório Flexner: consequências para a prática clínica}

Nos últimos dois séculos, a medicina se afastou do paciente (sujeito) e de seu sofrimento como objetos de ação e legitimou seu foco na doença, na lesão e na incorporação e valorização de uma tecnologia instrumental, diagnóstica e terapêutica, que representou o que $\mathrm{Luz}^{6,8}$ denominou de "medicina centrada no procedimento".

O paradigma cartesiano do organismo humano levou a uma abordagem tecnobiocientífica da saúde, na qual a doença é reduzida à avaria mecânica, e a terapia médica, à manipulação técnica. A tecnociência médica desenvolveu métodos altamente sofisticados para remover ou consertar diversas "peças" (partes) do corpo, com importantes êxitos ${ }^{6-8,41}$. No campo do saber médico, a influência desse paradigma sobre a racionalidade médica resultou no chamado modelo biomédico, base consensual da moderna medicina científica ${ }^{6,22,41}$. Esse modelo concebe o corpo humano como uma máquina complexa, que obedece a leis naturais e psicologicamente "perfeitas" e que necessite constantemente de inspeção por parte de um especialista ${ }^{6,7,22,41}$. 
Koifman ${ }^{41}$ destaca que, dentro desse modelo, os fenômenos biológicos são explicados pela química e pela física. Para essa autora, parece não haver espaço para os aspectos sociais, culturais, psicológicos e para as dimensões comportamentais do processo de adoecimento. Assim, as doenças são resultados ou de processo degenerativo dentro do corpo, ou de agentes químicos, físicos ou biológicos que o invadem, ou, ainda, da falha de algum mecanismo regulatório do organismo. De acordo com essa visão, as doenças podem ser identificadas somente pela ciência, e os tratamentos médicos consistem em esforços para reestruturar o funcionamento normal do corpo, para intervir nos processos degenerativos ou para eliminar invasores $6,22,41$.

A epistemologia de Canguilhem ${ }^{42}$ sobre o normal e o patológico torna mais complexa a abordagem da prática médica, que, impregnada de reducionismo organicista, colaborou para a fragmentação do indivíduo. A consequência mais visível dessa fragmentação foi o distanciamento médico-paciente. Canguilhem ${ }^{42}$ sinaliza ainda que a racionalidade anatomoclínica, imanente ao modelo biomédico, revelou-se insuficiente, pois excluiu da prática clínica aspectos psicossocioculturais relacionados ao processo de adoecimento.

A incorporação excessiva da tecnociência biomédica na prática clínica dos profissionais de saúde passou a produzir, em graus variáveis, efeitos colaterais, tais como interferência na relação profissional-paciente; culpabilização dos sujeitos pelo seu adoecimento; novos riscos; iatrogenia; graus exagerados de especialização; institucionalização dos cuidados de saúde; elevação nos custos dos serviços; comprometimento na alocação de recursos no sistema de saúde ${ }^{7-9,41}$.

A medicina social, entendida como possível alternativa para a tecnobiociência, não emerge apenas no século XX em função da especialização e da tecnificação da medicina e dos problemas decorrentes dessa fragmentação ${ }^{19,41}$. Em tangência com a consolidação do capitalismo no final do século XVIII e início do século XIX, a medicina social legitimou o corpo como biológico, força de
Estado, produção e trabalho. Nesse contexto, a medicina social nasce como estratégia biopolítica para controle do corpo, e as vertentes humanas relacionadas à comunicabilidade e subjetividade são postas de lado7-9,19.

Por volta de 1850, na Inglaterra e na Alemanha, a medicina já concebia que as relações entre saúde e doença e condições socioeconômicas deveriam ser investigadas pela ciência. Tais bases científicas e ideológicas corroboraram para apresentação de diversas leis, dentre elas a Lei de Saúde Pública na Alemanha: o Estado deveria providenciar um número de médicos bem treinados para atuar no combate à doença ${ }^{43}$. Já na Inglaterra, criou-se a Lei dos Pobres, que favoreceu, consubstancialmente, o surgimento de uma medicina social em que a base fundamentadora era o controle médico do pobre: "os pobres encontrando a possibilidade de se tratarem gratuitamente ou sem grande despesa e os ricos garantindo não serem vítimas de fenômenos epidêmicos originários da classe pobre"19.

Cabe resgatar aqui, também, como ocorreu o processo de embriogênese hospitalar nesses países. Segundo Foucault ${ }^{20}$, o hospital, antes do século XVIII, era regido por pessoal religioso, caritativo ou leigo, que, ao realizar uma obra de caridade, estava assegurado da salvação eterna. O hospial, nesse período, era considerado um morredouro. Somente na metade do século XVIII, perante uma nova maneira de pensar o hospital como aparelho de cura, a distribuição de seu espaço passou a ser instrumento terapêutico: a ordem religiosa responsável, até então, por assegurar a vida cotidiana hospitalar, a salvação e a assistência alimentar das pessoas foi substituída pela figura do médico ${ }^{20}$.

A partir desse momento, instalou-se no interior do hospital uma hierarquia em que enfermeiros, assistentes e alunos estavam subordinados à ordem médica. Dessa maneira, ficou balizado que o saber médico passaria a ter sua configuração centrada não mais nos grandes tratados clássicos de medicina, como era no início do século $\mathrm{XVIII}$, mas no que era cotidianamente registrado no hospital ${ }^{20}$. Nasceu, assim, dentro dessa lógica 
hospitalocêntrica, o que Foucault ${ }^{21}$ denominou de "clínica médica", que passou a ser dimensão essencial de construção e transmissão do saber médico hospitalar, em que a formação normativa de um médico deveria ser consolidada. Estava lançado o desafio para a formulação de um projeto no qual o ensino teórico e sistematizado das doenças estivesse atrelado à prática à beira do leito do doente. Esse projeto poderia ser sintetizado em poucas palavras: experiência clínica ${ }^{21,44}$.

Para Foucault ${ }^{21}$, a clínica - por um prisma histórico-cultural, "incessantemente invocada por seu empirismo, pela modéstia de sua atenção e pelo cuidado com que permite que as coisas silenciosamente se apresentem ao olhar, sem perturbá-las com algum discurso - deve sua real importância ao fato de ser uma reorganização em profundidade não só dos conhecimentos médicos, mas da própria possibilidade de um discurso sobre a doença".

Até os dias atuais, as instituições hospitalares ocupam na sociedade ocidental lugar central e quase naturalizado no que diz respeito à prestação de serviços voltados à saúde, à doença e à morte. Não apenas o médico passa a ter sua formação clínica centrada nessa instituição, mas os demais profissionais de saúde, incluindo o nutricionista ${ }^{22}$.

Já no cenário dos países das Américas, tem-se no chamado Relatório Flexner o marco central para a estruturação do modelo biomédico na formação médica. Proposto, em 1910, pelo professor Abraham Flexner, da Universidade Johns Hopkins, esse relatório foi produto da primeira grande avaliação do ensino médico realizada nos Estados Unidos e no Canadá, e se constitui o documento responsável pela mais importante reforma das escolas médicas desses dois países, influenciando profundamente a formação médica e a medicina moderna ${ }^{41,45}$.

De acordo com Pagliosa \& Da Ros ${ }^{45}$, com o propósito de fundamentar cientificamente a formação médica, o Relatório Flexner apresentou uma série de recomendações, tais como a expansão do ensino clínico, valorizando o espaço hospitalar como meio para o ensino prático, a ênfase na pesquisa biológica e o incentivo à especialização. A partir da análise desses autores, a medicina deve ter como foco a doença, que se apresenta como um processo natural e meramente biológico, corroborando, assim, a concepção do modelo biomédico, negligenciando os aspectos socioculturais e psicológicos. Embora tenha contribuído para reformulação e modernização do currículo de medicina, nele imprimiu características reducionistas, biologicistas, individualizantes e de especialização médica, com ênfase na medicina curativa e exclusão das medicinas integrativas e complementares. Essa proposta de organização curricular da formação médica, bem como da formação de outros profissionais de saúde, mostrou-se em evidência ao longo do século XX nos países americanos até a atualidade $22,41,45$.

O resultado mais expressivo de uma prática clínica, conformada na biomedicina e no modelo flexneriano, seria o que Campos ${ }^{4}$ denomina de "clínica clínica" (ou a clínica oficial), em que os profissionais de saúde atuariam no sentido de implementar a racionalidade tecnobiocientífica em sua totalidade. Por sua vez, a medicina, a nutrição e outros cursos da área da saúde operam com objeto de estudo e de trabalho reduzido aos aspectos biomédicos e epidemiológicos, o que redunda em insuficiência tanto para seu campo de saberes quanto para seus métodos e técnicas de intervenção. Dessa forma, a clínica oficial, ao se responsabilizar pela doença, deixando em segundo plano o doente, desresponsabiliza-se pela dimensão integral dos sujeitos $3-5,8,9,18,46$.

Nas duas últimas décadas, a clínica tem sido influenciada por novos contextos e expectativas de atenção à saúde, provocados pelas transformações estruturais no modelo assistencial do Sistema Único de Saúde (SUS), a exemplo das mudanças que vêm ocorrendo na atenção primária e em seus novos arranjos e cenários de práticas ${ }^{8,17,18,46}$. Em face desse cenário, Schraiber ${ }^{24}$ afirma que, ao mesmo tempo em que experimentam notável desenvolvimento tecno-científico, as práticas em saúde vêm enfrentando, já por algum tempo, uma sensível crise de legitimação. Desse 
modo, os novos problemas e necessidades na área da saúde geraram contradições, principalmente, entre o paradigma biomédico e o paradigma da construção social da saúde, construção essa calcada no fortalecimento do cuidado e da promoção à saúde, na ação intersetorial, na interdisciplinaridade e na crescente autonomia dos sujeitos em relação à saúde, visando à reorientação das relações entre profissionais de saúde e usuário 3,4,8,10,11,18,28.

Estudiosos como Caprara \& Franco ${ }^{1}$ corroboram essa discussão na medida em que apontam para a necessidade de a atuação do médico neste início de século XXI ser repensada a partir de novas perspectivas. Para esses autores, a relação médico-paciente, sustentada no modelo biomédico, não é mais suficiente para organizar os sistemas de saúde de forma efetiva, pois com todos os recursos tecnológicos existentes para lidar com cada fragmento do ser humano, falta ao médico a habilidade para lidar com o indivíduo em sua integralidade.

Para Boltanski ${ }^{47}$, a relação médico-paciente é marcada por elevada verticalidade e baixa densidade comunicacional: o médico, fazendo-se de seu discurso tecnobiocientífico, impõe sobre o paciente um ideal de um saber intelectualizado, tecnicista e detentor da cura, alheio a sua realidade. Nessa direção, vincula-se entre ambos uma relação de distanciamento, opondo-se, portanto, à perspectiva de humanização do atendimento médico e do direito do paciente ao entendimento da informação e à participação no seu processo terapêutico 1,2,4,17.

Há de se considerar que os profissionais de saúde e pacientes, mesmo pertencendo a uma mesma macrocultura, apresentam - devido às visões e aos sentidos simbólicos construídos por esses atores sociais em consonância com os seus distintos contextos microssocioculturais ${ }^{1-4,11,18}$ interpretações semânticas diferentes acerca do processo saúde-doença-cuidado. Dessa forma, a relação profissional de saúde e paciente tem sido enfocada como um aspecto-chave para a melhoria da qualidade do serviço de saúde prestado, de modo que a personalização da assistência, a humani-zação do atendimento e o direito à informação de qualidade têm sido levados em consideração como grau de satisfação do usuário do serviço de saúde ${ }^{1-4}$.

A construção do modelo biomédico, que, inicialmente, foi adotado nas escolas de medicina e influenciou todo o desenho das disciplinas ensinadas no campo das ciências da saúde, incluindo a nutrição, de certo modo, explica a dificuldade encontrada até os dias atuais na implementação de abordagem mais humanista na prática clínica ${ }^{10,11,22,25,28}$. Os estudantes da área de saúde, quando em contato com disciplinas fundamentais, como anatomia, por exemplo, são apresentados a peças, pedaços do corpo humano, raramente ao corpo inteiro. Há, assim, uma objetação do corpo jamais encontrada posteriormente pelo aluno $^{48}$, o que gera uma relação objetal com o outro, que incidirá numa crise de ajustamento quando os estudantes se depararem com o paciente como corpo de desejo, corpo de opinião, corpo de dor ou de prazer $^{48}$. Vale ressaltar que não estão os profissionais da nutrição isentos de tal experiência. Perante essa problemática, Ayres ${ }^{18}$ vislumbra a assistência clínica como processo capaz de integrar o outro e sua alteridade, no entanto considera que para alcançar esse propósito é essencial o desenvolvimento de novos saberes.

Observa-se, nesse contexto, a necessidade de rompimento com paradigmas na perspectiva da construção de outras racionalidades no que diz respeito às experiências comunicacionais entre profissionais de saúde e paciente, de forma que eles estejam em harmonia com os valores subjetivos do indivíduo, sua autonomia e vivências socioculturais, assim como com os princípios que norteiam as práticas em saúde, sobretudo, no âmbito do SUS 1,2,8,10,11,15,49.

\section{Ponto de continuação}

\section{Da configuração do nutricionista à especialização em nutrição clínica: as raízes da problemática}

A emergência do campo da nutrição, seja como prática social e/ou profissão no panorama 
mundial, é um fenômeno recente que data do início do século XX. Segundo evidências históricas, foi com o advento da revolução industrial europeia, entremeada pela Primeira Guerra Mundial no século XX, que se começou a pensar na constituição desse campo científico ${ }^{37}$.

No período entre as duas Guerras Mundiais, tanto em países europeus (Inglaterra, França entre outros) como em norte-americanos (Estados Unidos e Canadá) e, posteriormente, latino-americanos (Argentina e Brasil), foram fundados os primeiros centros de estudos e pesquisas, cursos para formação de profissionais especialistas e agências condutoras de medidas de intervenção nutricional $^{37}$.

Nos países latino-americanos, a nutrição se estrutura sob a forte influência do médico argentino Pedro Escudero, criador do Instituto Nacional de Nutrição em 1926, da Escola Nacional de Dietistas da Universidade de Buenos Aires, que oferecia o curso de médicos "dietólogos", e das leis que regem a nutrição (lei da qualidade, quantidade, harmonia e adequação) ${ }^{37}$.

No Brasil, a nutrição, de acordo com alguns estudos $^{37,50}$, teria surgido, no emanar dos anos 1930-1940, como parte integrante do plano de modernização da economia brasileira, dirigido pelo chamado Estado Nacional Populista, cuja conjuntura histórica demarcou a implantação das bases para a consolidação de uma sociedade capitalista urbano-industrial no país. Nasce, assim, a "figura do nutricionista" em um contexto social com modo de produção capitalista e com funções voltadas para as determinações estatais.

Relatos históricos dos primeiros anos da década de 1930 confirmam que tanto no Rio de Janeiro como em São Paulo e, posteriormente, em Salvador e no Recife, duas correntes bem definidas e conspícuas do saber médico corroboraram para a constituição do campo da nutrição ${ }^{37}$. Em um extremo, encontravam-se os adeptos da corrente com perspectiva biológica - cuja atuação era voltada para o individual, o doente, a clínica, a fisiologia e o laboratório -, preocupados essencialmente com aspectos clínico-fisiológicos associados ao consumo e à utilização biológica dos nutrientes e influenciados por pontos de vista das escolas de nutrição e dietética norte-americanas e de centros europeus ${ }^{37}$. A partir de 1940, essa vertente deu origem à nutrição clínica (dietoterapia) - considerada a especialização matriz do campo da nutrição dentro do cenário mundial, direcionada para ações nutricionais de caráter individual, focalizadas no "alimento como agente de tratamento de doenças" - e à nutrição básica e experimental. Em outro extremo, encontravam-se os partidários das ideias da corrente de perspectiva social, preocupados, particularmente, com aspectos relacionados à produção, à distribuição e ao consumo de alimentos pela população brasileira e influenciados, principalmente, pelas concepções de Pedro Escudero e Josué de Castro. Na década de 1940, essa última vertente deu origem à alimentação institucional (alimentação coletiva): outra especialização da nutrição também considerada matriz ${ }^{37}$.

Os aspectos históricos sobre a configuração do nutricionista e da nutrição clínica permitem salientar ainda que, a partir da década de trinta e nas duas seguintes, com o desenvolvimento e consolidação do capitalismo na América Latina, despontou também a capitalização do setor saúde, que culminou com a necessidade da especialização na formação profissional. Dessa maneira, a especialização em saúde tem sido um dos aspectos marcantes no panorama histórico de países com significativo desenvolvimento socioeconômico ao longo desse século, a exemplo do Brasil24,50.

Na década de 1950, as escolas de nutrição produziam dietistas cujo trabalho era restrito à administração de serviços de alimentação e dietoterapia hospitalar: era o começo do desenvolvimento tecnológico e científico na área ${ }^{37}$. Segundo Vasconcelos ${ }^{37}$, ao médico nutrólogo, por conta da sua especialidade na moderna nutrologia e conhecimento de fisiopatologia, competiria a orientação clínica e dietoterápica em relação ao doente, enquanto "as dietistas" seriam suas auxiliares diretas, cabendo-Ihes apenas o papel de 
executante da prescrição médica por meio de funções de auxiliar ou chefia de serviços dietéticos hospitalares.

Por volta de 1960, observa-se a preocupação com o diagnóstico nutricional, sendo tal prática enfatizada a partir desse período no país. Há, então, avanços nas perspectivas preventiva e curativa, o que eleva o profissional da categoria dietista para a de nutricionista ${ }^{37}$. Portanto, como consequência das transformações na divisão técnica do trabalho na saúde, novos especialistas surgiram nesse setor, dentre eles o nutricionista clínico, cujos primeiros passos contornavam o desenvolvimento da prática hospitalar de assistência nutricional ao paciente enfermo. Nesse cenário, o nutricionista clínico emerge no Brasil sob a égide de uma perspectiva biologicista estabelecida por interesses estatais e mercantis burgueses e na condição de subalterno aos médicos nutrólogos, concernente ao modelo hospitalocêntrico predominante ao longo desses anos ${ }^{25,37,50}$.

A partir de 1970 houve uma crescente solidificação dos cursos de nutrição no Brasil devido à demanda crescente de nutricionistas bem como do processo de expansão da área de ensino superior, esta última sendo muito impulsionada pela criação do II Programa Nacional de Alimentação e Nutrição (II Pronan), que continha em suas diretrizes o estímulo à formação de recursos humanos em nutrição 25 .

O currículo estabelecido em 1964, e predominante até o engendramento das reformas curriculares nas décadas de 1970 e 1980, era constituído por dois grupos de disciplinas: as básicas (anatomia, fisiologia humana, histologia, bioquímica, bromatologia, dietética, psicologia e microbiologia) e as profissionalizantes (fisiopatologia dos distúrbios nutricionais, técnica dietética, arte culinária, administração dos serviços de refeições, sociologia e economia aplicadas, dietoterapia, puericultura e dietética infantil, higiene e administração de saúde pública, pedagogia aplicada à nutrição, estatística e inquéritos alimentares). Criada em Bogotá em 1973, a Comissão de Estudos e Programas Acadêmicos de Nutrição e Dieté- tica na América Latina (CEPANDAL) passou, então, a servir de referência para as discussões curriculares que se sucederiam na década seguinte ${ }^{25}$.

A conferência de Alma Ata (1978) foi um marco importante na redefinição das políticas do setor saúde, assumindo como princípio fundamental o processo de reorganização dos serviços de saúde centrados na atenção primária. Assim, novos temas têm emergido no campo da saúde, tais como o enfoque biopsicossocial, a interdisciplinaridade, o respeito à diversidade cultural, as novas tecnologias em saúde, a releitura da bioética e o impacto das novas tendências econômicas nas políticas de saúde ${ }^{18,25,51}$. A partir desse ponto, há então uma discussão aprofundada sobre o processo de formação dos profissionais de saúde, sendo discutidas as necessidades de mudanças substanciais no processo formativo, sobretudo no relacionado ao perfil profissional desejado e à adaptação do modelo pedagógico para o alcance dos objetivos. São definidas estratégias para integração entre o mundo do ensino e do trabalho, ênfase na formação generalista, trabalho multiprofissional, diversificação dos cenários de prática e adoção de metodologias ativas de aprendizagem $^{25}$. Embora tenham ocorrido avanços na tradução dessas demandas em conteúdos e atividades curriculares, esses ainda são incipientes 28,51 .

Obviamente que são notáveis os avanços conquistados pela categoria ao longo dessas oito décadas de mobilização, organização e luta em busca de legitimidade, autonomia e identidade profissional ${ }^{37}$. No entanto, observa-se ainda que os cursos de nutrição, compreendidos na lógica fragmentada dos saberes em saúde, em sua maioria conjecturada dentro do modelo biomédico, têm dado pouca ou nenhuma importância às dimensões humana e social dos sujeitos na trajetória de formação acadêmico-profissional do nutricionista $25,28,50$, bem como não têm tratado devidamente o tema "alimentação" como fenômeno psicobiossociocultural ${ }^{10,11,13,28,35,36,38}$. Isso passa a ser preocupante na medida em que os elementos de trabalho desse profissional são o homem e sua comida: um processo relacional demasiadamente complexo ${ }^{11,28,33-36,38-40}$. 
Bosi ${ }^{25}$, ao realizar uma avaliação dos cursos de nutrição no Brasil na década de 1980, identificou grande desproporção entre as disciplinas biológicas (predominantes) e sociais. Segundo a autora, tal desproporção entre as áreas contribui para uma insuficiente compreensão do social na formação do nutricionista, originando profissionais com olhar fragmentado no cuidado nutricional.

Motta et al. ${ }^{51}$, por meio de pesquisas em sites da Internet, analisaram o posicionamento de 71 cursos de nutrição sobre sua missão e observaram escassas menções sobre o caráter crítico e o compromisso com as transformações sociais. A formação ética e humanística foi um dos itens mais desvalorizados na divulgação dos cursos; prevaleceu a identificação do nutricionista como profissional de saúde e, acima de tudo, a valorização do mercado de trabalho.

Estudiosos como Bosi ${ }^{25}$ e Santos et al. ${ }^{28}$ reconhecem que, embora tenham sido realizados esforços para tentar equilibrar o currículo de cursos de nutrição, ainda persiste desarticulação importante entre o biológico e o sociocultural na formação e prática clínica do nutricionista.

Considerando a revisão de literatura e os aspectos abordados, foi possível perceber que, no campo da nutrição, há certa escassez de referências sobre o histórico da nutrição clínica no Brasil e seus fundamentos epistemológicos. Os poucos estudos identificados na literatura sinalizam a influência da racionalidade biomédica na conformação da nutrição clínica ${ }^{10-14,25,35}$. Em que pese a influência na construção histórica da nutrição clínica ser marcada pela história da conformação do campo da clínica médica, esta não pode ser tomada apenas como uma mera consequência da primeira. Urgem estudos que aprofundem suas particularidades, explicitando questões como o quanto o modelo biomédico é capaz de responder às demandas referentes à alimentação e à nutrição do corpo humano. Em outras palavras, ao considerar as múltiplas funções da dieta no corpo humano, seria possível reduzi-la a uma prescrição medicamentosa tal como ocorre na medicina especializada, que foca a doença e não o pacien- te? Em suma, essa problemática ilustra que o elo entre o corpo (do sujeito) e a dieta é mais amplo e precisa ser aprofundado.

\section{Da nutrição clínica ampliada como possibilidade para reflexão acerca da humanização da relação nutricionista-paciente}

Dentre as diversas áreas de prática do nutricionista como profissional de saúde, destaca-se a nutrição clínica. Essa área pode ser caracterizada como aquela que se desenvolve em hospitais, clínicas, consultórios e outros, na qual o nutricionista clínico realiza atenção dietoterápica ao paciente baseada, principalmente, no seu quadro clínico e diagnóstico nutricional52.

A Associação Americana de Diabetes $(A D A)^{53}$ define a atenção dietoterápica como um processo que vai ao encontro às diferentes necessidades nutricionais de um indivíduo, o que inclui a avaliação do seu estado nutricional, a identificação das suas necessidades ou problemas nutricionais, o planejamento de objetivos de cuidado nutricional que preencham essas necessidades, a implementação de ações dietéticas e a avaliação da atenção dietoterápica. Boog ${ }^{32}$, Freitas et al. ${ }^{10,11}$ e Freitas ${ }^{26}$ assinalam que os aspectos sensoriais, psicológicos e socioculturais também devem estar envolvidos na atenção dietoterápica. Sousa \& Proença ${ }^{54}$ afirmam que, para a efetivação da conduta dietoterápica no âmbito hospitalar, são necessárias ações articuladas entre os setores de produção de refeições e de atendimento clínico-nutricional.

Pesquisa nacional realizada pelo Conselho Federal de Nutricionistas (CFN) ${ }^{52}$, envolvendo 2434 nutricionistas, com o propósito de identificar o perfil de atuação profissional no mercado de trabalho, revelou que 44,9\% atuavam na área de nutrição clínica, estando 52,9\% desses distribuídos entre hospitais, e 38,8\% em ambulatórios e consultórios.

$\mathrm{Na}$ atualidade, observa-se que a Nutrição Clínica tem se fragmentado em subáreas de 
atuação conforme o modelo biomédico organicista. Assim, encontram-se nutricionistas clínicos atuando por grupos biologicamente vulneráveis ou outras especializações médicas, por exemplo, nutricionista clínico atuando em Obstetrícia, Pediatria, Geriatria, Gastroenterologia, Hepatologia, Cardiologia, Endocrinologia (principalmente, obesidade e diabetes), Nefrologia, Cirurgia, Oncologia e em Saúde Mental (Transtornos alimentares). Vale antecipar que não é intenção deste trabalho desconsiderar a importância dos especialistas em nutrição clínica para o campo da nutrição e saúde, bem como os benefícios que este grupo profissional tem gerado para a sociedade. Parte-se do pressuposto que a incorporação tecnológica e especialização exageradas em nutrição e saúde, ao deixar de abarcar as subjetividades, dilui a responsabilidade pela atenção nutricional e dificulta o desenvolvimento de relação nutricionista-paciente comprometida com a dimensão humana e projetos socialmente transformadores. Esses fatos primam por uma discussão acerca do modo de atuação do nutricionista em nutrição clínica, sobretudo, nos espaços do SUS, considerando que as práticas nestes espaços devem se pautar no cuidado integral do ser humano ${ }^{49}$.

Historicamente, o nutricionista clínico, ao prestar atendimento a pacientes portadores de problemas nutricionais e de saúde, vem minimizando seus valores subjetivos e a promoção de sua autonomia, reduzindo-o praticamente à sua doença ("o obeso", por exemplo), não o vendo, portanto, como um ser (sujeito) que possui historicidade, culturalidade e temporalidade 10,34-36,55. Freitas et al. ${ }^{11}$ sinalizam para certo distanciamento existente na relação nutricionista-paciente, estabelecido na prática clínica, que se opõe ao que os autores denominam de perspectiva hermenêutica de humanização.

A partir de um prisma epistemológico sobre a prática clínica do nutricionista, nota-se que ela não tem sido plenamente fundamentada nos princípios humanísticos, conforme orienta a Política Nacional de Humanização (PNH) do SUS 10,13,15,22,49. Evidentemente que nessa afirmativa não se considera que o encontro terapêutico entre nutricionistas e pacientes seja marcado por práticas "desumanas". A crítica que se faz é sobre a forma de humanização vigente na prática clínica nutricional, a qual não deve se firmar apenas no plano humanista-assistencialista, mas integrar os princípios técnicos e tecnológicos com os princípios éticos e relacionais no cuidado clínico-nutricional em saúde.

O debate sobre a humanização no âmbito da saúde teve início em cenário no qual ele era secundarizado e/ou banalizado por grande parte dos gestores e trabalhadores e reivindicado tanto pelos usuários quanto por trabalhadores, buscando uma atenção com acolhimento, de forma resolutiva e lutando por melhores condições de trabalho. Assim, o conceito se expressava em ações fragmentadas, frágeis e imprecisas, atreladas ao voluntarismo, assistencialismo, paternalismo ou mesmo ao tecnicismo de um gerenciamento alicerçado na racionalidade administrativa e na qualidade total. Para que ocorresse um processo de mudança intenso, respondendo aos anseios dos usuários e trabalhadores da saúde no âmbito do SUS, foi necessário enfrentar desafios conceituais e metodológicos ${ }^{15,16,56}$, que representaram um marco para a formulação e consolidação da $\mathrm{PNH}^{49}$. Como política, a humanização deve, portanto, traduzir princípios e modos de operar no conjunto das relações entre trabaIhadores e usuários, entre os diferentes trabalhadores, entre diversas unidades e serviços de saúde e entre instâncias que constituem o SUS 15,49,56.

É nesse sentido que diferentes autores, como Luz ${ }^{8}$, Freitas et al. ${ }^{10,11}$, Amorim et al. ${ }^{12}$, Solymos $^{13}$, Bosi1 ${ }^{14,25}$, Goulart \& Chiari15, Deslandes \& Mitre $^{16}$, Diez-Garcia ${ }^{31}$ e Scagliusi et al. ${ }^{35}$, expressam a necessidade de um processo de humanização da nutrição, em particular da relação entre nutricionistas e pacientes, reconhecendo a necessidade de uma maior sensibilidade e densidade comunicacional diante do sofrimento do paciente portador de enfermidade. Essa proposta inspira uma nova identidade profissional, responsável pela efetiva promoção da saúde ao considerar o paciente em sua integridade física, psíquica e sociocultural, e não somente de um ponto de vista 
biológico. O desenvolvimento dessa sensibilidade e sua aplicação na prática clínica constituem importante desafio para a nutrição clínica do século $\mathrm{XXI}$.

Assim, entende-se o processo de humanização da nutrição como a capacidade de oferecer cuidado nutricional de forma integral e qualificado, valorizando o diálogo e a escuta em suficiência na relação profissional-usuário e articulando o conhecimento tecnocientífico das áreas de alimentação, nutrição e saúde com princípios ético-humanísticos, com aspectos psicossocioculturais do ser humano, acolhimento, melhoria do ambiente de cuidado nutricional e das condições de trabalho dos nutricionistas. Segundo Boff ${ }^{57}$, o cuidado humanizado não deve ser tratado como uma intervenção sobre o paciente: "[...] a relação não é sujeito-objeto, mas sujeito-sujeito. Experimentamos os seres como sujeitos, como valores, como símbolos". "A relação do cuidado não é de domínio sobre, mas de convivência, não é pura intervenção, mas interação".

Onfray ${ }^{23}$, filósofo francês, em sua obra $O$ ventre dos filósofos - crítica da razão dietética, retrata, sob a forma de autobiografia alimentar, a relação estabelecida com uma nutricionista no âmbito do cuidado nutricional hospitalar, após ter sido acometido por infarto agudo do miocárdio, a saber:

[...] Os pesares da existência se evaporam quando nos encontramos, entre amigos, ao redor de uma mesa [...]. Para amedrontar todos eles, veio-me a impertinente e má ideia de um enfarte no final do ano de 1987. Essa pilhéria teve sua conveniência pois graças a esse delírio das artérias que devo as páginas que se seguem. Todos se espantaram: as estatísticas não me tinham previsto, achavam a insolência um pouco absurda. Um enfarte aos 28 anos [...]. Entre dois eletrocardiogramas, uma injeção de Calciparine e um exame de sangue, o destino manifestou-se na forma de uma nutricionista [...]. Ela me deu um curso chato sobre uso da alimentação para monge do deserto. Na véspera do acidente cardíaco, uma refeição a seis ou sete me permitira preparar um carneiro com cogumelos. E eu precisava rezar pela alma de tudo isso para me dedicar ao regime hipocalórico, hipoglicêmico e hipocolesterólico. Era o mesmo que eu trocar meu livro de receitas por um dicionário de medicina [...]. A funcionária das calorias me fez uma conferência sobre os méritos dos cremes e leites desnatados e dos cozimentos em água. Nada de moIhos borbulhantes e engrossados farinhentos! Era preciso me converter às ervas e às verduras [...]. Num sobressalto de heroísmo declarei, como última palavra antes de passar dessa para melhor, que preferia morrer comendo manteiga do que economizar minha existência à custa de margarina. Psicóloga como ela só, mas medíocre dialetóloga, ela retorquiu, em desprezo a qualquer lógica elementar, que a manteiga e a margarina eram a mesma coisa [...]. Ela era mais hábil nos oligoelementos do que na dialética, eu lhe disse do fundo da cama que eu preferia a manteiga [...] já que era a mesma coisa. Basta! A discussão tornava-se azeda. Ela declarou que me abandonava à obesidade - eu acabara de perder sete quilos -, ao colesterol e à morte próxima [...]. Algum tempo depois da dietética dos centros hospitalares e de readaptação, voltei à vida normal [...] isto é, à cozinha normal. Para preparar a minha nutricionista espertinha um prato ao meu lado, lembrei-me que um conjunto de receitas para uma gaia ciência alimentar não seria demais. Era preciso à policial uma lição de hedonismo. Eis por que estas páginas existem [...].

O exemplo aqui trazido, de relação nutricionista-paciente, ilustra uma humanização assistencialista na abordagem nutricional hospitalar na medida em que se observa desarticulação entre os saberes científicos (não biomédico e biomédico) e os saberes do senso comum e artísticos, na atenção dietoterápica com o paciente, na qual a nutri- 
cionista em questão não leva em consideração, por exemplo, aspectos da "nutrosofia" e filosofia do gosto, como a gastronomia e o hedonismo. 0 discurso normativo e restrito sobre a alimentação apregoado na clínica nutricional atua como um imperativo para o "bem-estar" do corpo. Nessa perspectiva moral e racional, negam-se a tradição das sensações e dos temperos, os padrões culinários mais antigos e domésticos, para adotar outros modelos baseados em uma moral estética ou clínica ${ }^{27}$. Conforme referido por alguns autores $^{9,55,58}$, o paciente é culpabilizado pelo nutricionista por seu adoecimento, bem como pela não adesão ao plano nutricional proposto, como também ficou evidente na situação apresentada. Este fato pode acarretar problemas ligados ao preconceito social e estigma ${ }^{55}$. Ruiz-Moral ${ }^{5}$ alerta para a necessidade de se reconhecer as implicações psicológicas que, em qualquer relação humana, podem ocorrer, tais como: decepção com o profissional, culpabilização, depressão e objeções às alternativas sugeridas. Nota-se ainda que a nutricionista utiliza atitudes e discursos considerados racionais e de controle na relação profissional-paciente, deixando, assim, de humanizar de modo integral essa relação, tornando-a uma relação desinteressada, com insuficiência de diálogo, sensibilidade e afeto, que por seu turno dificulta que o paciente consiga estabelecer uma verdadeira relação de confiança com esse profissional.

Diante disso, torna-se necessário repensar esse modelo vigente na clínica nutricional. Scagliusi et al. ${ }^{35}$ trazem uma importante contribuição para essa reflexão. Segundo essas autoras, a abordagem clássica da nutrição tem se pautado em uma visão biológica ou "pós-deglutição". Nessa direção, o foco clínico-nutricional se encontra no que se come e não em como se come, ou seja, uma alimentação que não segue as diretrizes nutricionais é vista como inadequada (ou, pior ainda, como errada), e não como outra racionalidade possível e, por isso, interessante, haja vista que ela carrega consigo uma história a ser narrada. Portanto, não se pretende com essa discussão desconsiderar a relevância de uma alimentação balanceada que atenda as necessidades nutricionais. A nutrição adequada das células e a "boa saúde" são objetivos nutricionais importantes, entretanto não devem ser tomadas como objetivos plenos, uma vez que a abordagem biológica da nutrição apresenta limitações significativas e premissas que precisam ser discutidas ${ }^{35}$.

A abordagem biológica da clínica-nutricional está intimamente relacionada ao processo de medicalização, o qual pode ser compreendido como a incorporação de terminologia e abordagem médica ou nutricional para questões que não são apenas médicas ou nutricionais, mas, também socioculturais, políticas e econômicas ${ }^{9,35}$. Dessa forma, não só a comida desaparece do cenário clínico-nutricional, como também o alimento (seu "substituto melhorado") é tratado como remédio. Esta visão enquadra-se na "ideologia de saúde" ou healthism, na qual a saúde é vista como valor humano primário, devendo o ser humano viver para ser saudável ${ }^{9,35}$. Castiel \& Diaz ${ }^{9}$ e Scagliusi et al. ${ }^{35}$ corroboram essa discussão ao afirmarem que nessa ideologia é coerente que o paciente abandone seus sentimentos, valores e significados sobre a comida, para incorporar os novos alimentos apregoados pela racionalidade científica moderna, que podem ser sem história, sem graça, sem gosto e desprovido de memória, mas que o afastam do risco de "doenças futuras", tornado isso como o aspecto mais importante na sua vida. Emerge, a partir dessa visão, a figura do nutricionista policial que assume a incumbência de afastar o paciente do "mau caminho"9,23,35.

Nesse sentido, Freitas et al. ${ }^{27}$ fazem uma reflexão relevante para o campo da nutrição, especialmente para a área de nutrição clínica. Os autores discutem o processo de mudanças de hábitos alimentares e os sentidos atribuídos ao comer diante dos problemas nutricionais. Tomando como exemplo o problema da obesidade, doença de prevalência crescente no Brasil, os autores discutem cuidadosamente sobre a complexidade atrelada ao processo de mudança de hábitos alimentares. Desse modo, colocam que a obesidade não é uma questão somente do indivíduo (do corpo biológico), mas trata-se de uma enfermidade que também comporta determinantes psicossocioculturais. Afirmam ainda que o corpo obeso, originário, fundamentalmente, da 
formação de hábitos alimentares e estilos de vida modernos, vincula-se aos interesses da indústria e do mercado de alimentos. O contexto do indivíduo é obesogênico e, portanto, deve ser transformado.

Para exemplificar ainda que a prática clínica nutricional baseada apenas na racionalidade científica moderna ou biomédica pode levar à ineficácia das prescrições nutricionais e inefetividade do processo de mudança de hábitos alimentares e estilos de vida, são apresentados a seguir resultados de alguns estudos internacionais e nacionais.

Estudo epidemiológico realizado no México com indivíduos portadores de Diabetes Mellitus tipo 2 identificou que $62 \%$ deles não aderem ao plano nutricional recomendado ${ }^{59}$. Outro estudo, realizado no Brasil nessa mesma perspectiva, porém, envolvendo indivíduos portadores de obesidade, revelou que um grande número deles abandona o plano dietético de reeducação alimen$\operatorname{tar}^{60}$. Menéndez ${ }^{61}$ destaca que a maioria dos estudos epidemiológicos sobre os problemas nutricionais e de saúde caracteriza-se pela ausência total das discussões socioculturais ou pela presença de poucas notas, sem aprofundamentos. Por outro ângulo, resultados de investigação qualitativa ${ }^{62}$ realizada em uma unidade básica de saúde de Ribeirão Preto (São Paulo, Brasil), envolvendo mulheres portadoras de diabetes tipo 2, evidenciaram dificuldade no seguimento da dieta prescrita, em função dos múltiplos significados associados, tais como a perda do prazer de comer e beber, da autonomia e da liberdade para se alimentar. De acordo com essas mulheres, seguir o plano dietético recomendado revelou caráter extremamente aversivo e cerceador, e, portanto, realizá-lo implica prejuízos à saúde, além de o ato de comer, muitas vezes, vir acompanhado de medo, tristeza, culpa e revolta ${ }^{62}$.

Outro estudo qualitativo realizado em São Paulo por Diez-Garcia ${ }^{31}$, com indivíduos de dois hospitais (um público e outro privado) envolvidos no planejamento e produção da dieta hospitalar, revelou que as representações sobre a alimentação oferecida no hospital refletiam, de um lado, o caráter da hospitalização no que diz respeito à condição de controle e disciplina, da pouca autonomia e poder de voz do paciente, e, de outro, uma importância limitada da dieta hospitalar por parte dos atores que participavam, efetivamente, do atendimento e do gerenciamento hospitalar. Os resultados evidenciaram, também, as condições ainda incipientes do cuidado nutricional em nível hospitalar e dicotomia entre dieta e comida, representando a ruptura entre o prazer, o gosto e o aspecto nutricional, de modo a predominar a qualificação positiva da dieta por seu papel no atendimento às demandas biológicas que tampouco são efetivas na prática, sobretudo, quando se trata de alimentação via oral. Nesse sentido, a autora do estudo enfatiza que a alimentação hospitalar não deve oferecer somente as respostas nutricionais adaptadas ao tratamento do paciente; deve assegurar, além da função nutricional e higiênico-sanitária, outras funções, tais como a sígnica e hedônica.

Demário et al. ${ }^{63}$, ao estudarem as percepções de pacientes sobre a alimentação fornecida em um hospital com proposta de atendimento humanizado, observaram que o comer bem no hospital depende do que os pacientes podem ou não se alimentar devido a sua doença, revelando ser ausente a identificação da alimentação hospitalar com sua história alimentar, preferências ou hábitos adquiridos ao longo de sua vida.

Pontieri \& Bachion ${ }^{58}$ analisaram as crenças de pacientes portadores de Diabetes Mellitus tipo 2, atendidos em um ambulatório de referência do sistema público de saúde de uma cidade do Estado de Goiás, a respeito da terapia nutricional e sua influência na adesão dietética. Os resultados fornecidos por esse estudo remetem a um panorama atual sugestivo de certa massificação da prescrição e terapia nutricional. Para as autoras desse estudo, os nutricionistas estão restritos a conceitos e valores tecno-científicos, que não facilitam o processo de conhecimento pelos pacientes a respeito da terapia que está sendo instituída. Os pacientes recebem as orientações nutricionais de forma unilateral, deixando uma lacuna na qual caberiam a educação nutricional, o diálo- 
go alimentar e a construção coparticipativa do conhecimento.

Corroborando as discussões anteriormente apresentadas, Freitas et al. ${ }^{10}$ destacam que a prescrição dietética, traduzida sob a forma de orientação nutricional, é concebida pelo paciente como uma receita medicamentosa. Os nutrientes organizados como um receituário nutricional fazem oposição à tradição, aos hábitos e aos valores culturais do comer. A elaboração do receituário dietético na clínica sem a incorporação dos aspectos socioculturais da alimentação pode resultar no sofrimento do paciente, em desgostos e rupturas do cotidiano com seus valores e crenças culinárias. Assim, uma proposta humanizadora da relação nutricionista-paciente é a compreensão por parte do terapeuta nutricional quanto ao significado da alimentação para o paciente, a interpretação que ele faz sobre sua dieta, seu corpo em seu mundo ${ }^{10}$. Sabe-se que, na concepção biomédica, os nutrientes possuem diversas funções orgânicas e atuam sinergicamente no corpo não apenas em uma célula ou órgão específico, como ocorre, por exemplo, com um fármaco que a priori possui sítio-alvo de atuação no organismo. Dessa maneira, os alimentos não devem ser tratados apenas do seu ponto de vista nutricional, nutracêutico, nutrigenômico e funcional nas especificidades patológicas, mas também na sua pluralidade de sentidos e significados que assumem.

Pelo exposto, o entendimento da complexidade imanente a esses problemas remete à necessidade do nutricionista considerar também outros elementos semiológicos do paciente (emoções, sentidos, significados, valores, memória alimentar etc.) na elaboração do plano dietético. A desconsideração desses fatores por parte do profissional pode interferir negativamente na adesão ao tratamento nutricional ${ }^{10,11,26,33,36,58,60}$.

Nessa perspectiva, é necessário entender ainda que o ser humano não come apenas quantidades de nutrientes e calorias para manter o funcionamento do corpo em nível adequado. 0 comer não satisfaz apenas as necessidades nutricionais e biológicas, mas preenche também dimensões sócio-históricas, culturais e ecoló- gicas $27,30,31,40,64$. Fischler ${ }^{39}$ ressalta que se o homem "come tudo", ele "não come de tudo". Segundo esse autor, nem todo alimento biologicamente ingerível é culturamente comestível. $\mathrm{O}$ ato de se alimentar envolve seleção, escolhas, ocasiões e rituais, imbrica-se com a sociabilidade, com ideias e significados, com as interpretações de experiências e/ou interações cotidianas, não permitindo à sua abordagem visões unidimensionais $27,30,31,38,40,64$. O comer, de acordo com Poulain \& Proença ${ }^{40}$, desenrola-se em consonância com regras impostas pela sociedade, influenciando a escolha alimentar. Essas regras "são representadas pelas maneiras de preparo dos alimentos, pela montagem dos pratos e pelos rituais das refeições (como, por exemplo, os modos e as posições das pessoas à mesa, a divisão da comida entre os indivíduos, os horários estipulados, entre outros), contribuindo para que o homem se identifique com o alimento e por sua representação simbólica". Nesse sentido, o nutricionista deve assumir a alimentação como resultado da pluralidade e singularidade das interações entre o sociocultural e o biológico.

Tendo em vista a complexidade da abordagem em nutrição clínica e saúde ${ }^{11,15}$, Pedroso et al. ${ }^{65}$ argumentam que os serviços de saúde estão sendo direcionados no sentido de considerar não apenas a patologia, mas também as preferências, hábitos e aversões do indivíduo no atendimento nutricional. Entretanto, reconhecem que ainda há muito que avançar nesse sentido, sobretudo no que diz respeito à formação e prática clínica do nutricionista, pautadas na humanização e interdisciplinaridade. A despeito disso, as diferentes abordagens e significados que circundam a alimentação podem permitir ao nutricionista clínico aproximação maior e conhecimento cada vez mais profundo do indivíduo hospitalizado ou acompanhado ambulatorialmente, na sua totalidade, valorizando sua essência e respeitando sua individualidade na programação da terapia nutricional.

É valido ressaltar que o papel terapêutico dos alimentos tem evoluído devido ao avanço considerável dos conhecimentos relacionados à dietética e à nutrição. As pesquisas nessas áreas 
contribuíram com novos pontos de vista acerca da terapia nutricional, ficando cada vez mais evidente que a nutrição pode, de fato, apresentar função importante no processo saúde-doença ${ }^{66}$. Contudo, Fischler ${ }^{39}$ assinala que para melhor compreender as implicações das intervenções dietéticas nos hábitos alimentares a partir de razões sanitária, médica, nutricional, econômica e comercial, entre outras, deve-se levar em consideração as dificuldades e as consequências desconhecidas decorrentes do conhecimento ainda embrionário sobre a construção do comportamento alimentar. A tentativa de moldar o comportamento alimentar, segundo avanços e flutuações do conhecimento em alimentação e nutrição, não pode deixar de abarcar suas implicações técnicas, metodológicas, éticas e epistemológicas ${ }^{39}$.

Concernente aos fatos mencionados, como (re)pensar a relação nutricionista-paciente na prática clínica nutricional contemporânea no sentido de ampliar sua humanização?

Para suscitar esse debate, traz-se a contribuição da concepção da clínica ampliada, proposta por Campos \& Amaral $^{3}$, Campos $^{4}$ e Cunha ${ }^{17}$, para sugerir a ampliação do modelo de nutrição clínica biomédica a fim de contribuir para reflexão acerca da humanização da relação nutricionista-paciente na contemporaneidade.

Segundo Cunha ${ }^{17}$, a clínica ampliada é entendida como a "transformação da atenção individual e coletiva, de forma que possibilite que outros aspectos do sujeito, que não apenas o biológico, possam ser compreendidos e trabalhados pelos profissionais de saúde". O propósito dessa concepção e a produção de saúde nos diferentes espaços de promoção, prevenção, cura, recuperação e de cuidados paliatívos, bem como a ampliação do grau de autonomia do usuário, da família e da comunidade.

Na concepção da clínica ampliada, a ampliação da autonomia dos usuários dar-se-ia a partir de ações que visam à promoção dos sujeitos, capacitando-os a compreender melhor suas necessidades de saúde, entendendo seus agravos e participando como corresponsáveis no processo saúde-doença-cuidado 3,4,17,49.

Vale salientar que as reformas que vêm ocorrendo nos serviços de saúde, especialmente naqueles inseridos no âmbito do SUS, sem dúvida, envolvem inúmeros desafios ${ }^{49}$. Dentre eles, Campos \& Amaral $^{3}$ e Campos $^{4}$ destacam a necessidade de se reformarem saberes e práticas para reorientar tanto a clínica quanto a saúde coletiva. Seguindo nessa lógica, eles defendem que os cursos da área da saúde deveriam se voltar para a formação de profissionais capazes de resolver problemas de saúde, integrar-se em equipes multiprofissionais, reconhecer as determinações sociais, subjetivas e biológicas da saúde/doença, construir planos terapêuticos singulares e articulados a essas determinações, estabelecer vínculos e assumir responsabilidade em lidar com a cura e a recuperação dos pacientes. Campos \& $\mathrm{Amaral}^{3}$ propõem a formação do profissional de saúde para uma reforma cultural e epistemológica da clínica biomédica ("clínica clínica"), tornando-a uma clínica ampliada por meio da reorientação do campo de saberes, responsabilidades e práticas.

No tocante à prática clínica do nutricionista na contemporaneidade, a Figura 1 ilustra o modelo hegemônico de relação nutricionista-paciente vigente. Observa-se, com base na literatura consultada ${ }^{10-13,15,22}$, que a prática clínica nutricional biomédica, que se desenvolve no contexto com modo de produção capitalista, tem sido marcada pela verticalidade da relação nutricionista-paciente, que se caracteriza pela despersonalização do cuidado nutricional, baixa densidade comunicacional, humanização assistencialista e foco na doença e não no doente.

Como possibilidade para uma reformulação epistemológica e cultural da nutrição clínica biomédica ou oficial, propõe-se, a partir da concepção da clínica ampliada sugerida por Campos \& Amaral ${ }^{3}$, Campos $^{4}$ e Cunha ${ }^{17}$, a concepção de "nutrição clínica do sujeito" ou nutrição clínica ampliada que buscaria ir além do mecanicismo, da fragmentação e do tecnicismo biologicista na abordagem nutricional com o paciente (Figura 2). 


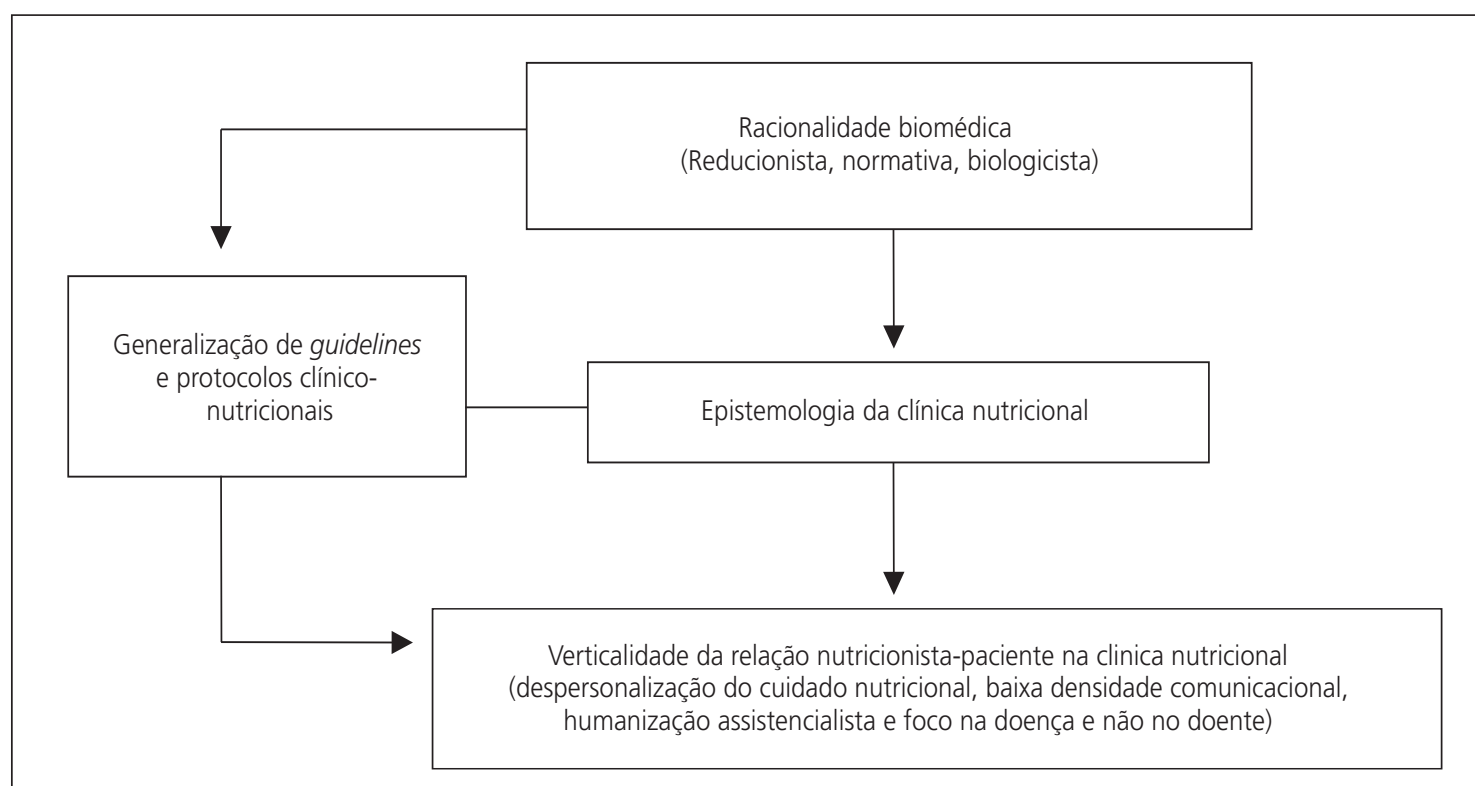

Contexto social com modo de produção capitalista

Figura 1. Matriz que representa a relação nutricionista-paciente na clínica nutricional biomédica.

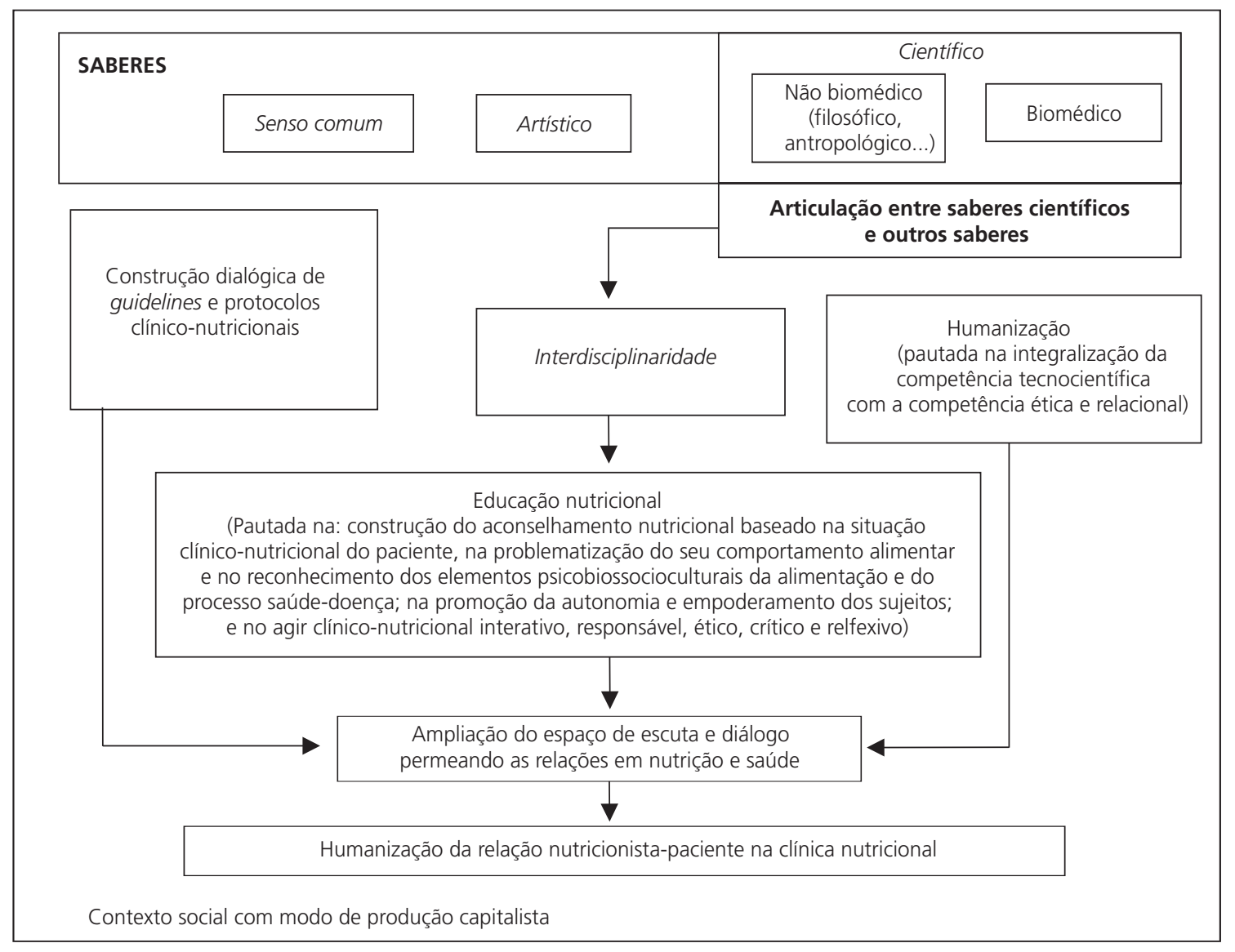

Figura 2. Proposta-matriz do modelo da nutrição clínica ampliada. 
Essa proposta aponta para a promoção da nutrição clínica voltada a reconhecer, interpretar e atuar sobre as necessidades de sujeitos que buscam o cuidado nutricional. Dessa forma, sua construção dar-se-ia a partir da práxis, isto é, da reflexão sobre os encontros e os diálogos. A nutrição clínica ampliada passa a ser entendida como um modelo ou novo modus operandi interdisciplinar em saúde - no qual a racionalidade nutricional se articula com outras formas de conhecimento (senso comum, artístico etc.) ligados à alimentação e ao ser humano -, que é refletido e retorna reflexivamente para os cuidadores e cuidados, de maneira a promover novas formulações e modos (e não, modas) de atuar em nutrição clínica e saúde. Espera-se com esse modelo que o nutricionista busque estabelecer competência dialógica com o paciente, isto é, compreenda e interprete as relações que fazem interagir dieta e cultura, os anseios do paciente, e proponha, nesse sentido, mudanças, traduzidas na forma de aconselhamento nutricional, que ao mesmo tempo considere o contexto sociocultural da comensalidade e acrescente a ele propostas novas, substanciais e possíveis de serem executadas no seu cotidiano.

Essa concepção prima ainda por uma prática clínica nutricional que incorpore a cultura de construção dialógica de guidelines ou protocolos clínico-nutricionais. Assim, os documentos iniciais devem ser elaborados pelos profissionais envolvidos (nutricionistas, nutrólogos entre outros), mas, em seguida, deve ser instituído um processo de avaliação e de reelaboração desses documentos pela equipe e por pessoas para quem eles serão direcionados. Essa nova concepção, ainda que inserida no modo de produção capitalista, gravita em torno das proposições da chamada humanização da atenção à saúde $3,4,41,13,15-18,35,46,67,68$.

Alvarenga \& Scaglius ${ }^{36}$ concordam com a necessidade de que o nutricionista amplie sua visão sobre nutrição e desenvolva outras competências na clínica nutricional. Estas autoras advogam que $o$ aconselhamento nutricional deve ser entendido como elemento para educação alimentar e nutricional que visa facilitar o crescimento do sujeito, sendo uma junção de expertise em nutrição e outras competências que enfatizem as vivências socioculturais associadas à alimentação. Assim, a realização do aconselhamento nutricional deve trazer à luz da prática clínica ampliada memórias e sentimentos do paciente ligados ao comer e à comida (e, por que não, à sua vida?); pautar-se na problematização do comportamento alimentar profissional-paciente, possibilitando a reflexão e escolha de estratégias nutricionais possíveis e viáveis para o paciente, podendo consistir ainda em processo eficaz e efetivo no que diz respeito às mudanças de práticas alimentares e estilos de vida ${ }^{27,33-36 . ~}$

Nessa perspectiva, sugere-se que o nutricionista tente realizar problematização do comportamento alimentar do paciente (sujeito) na abordagem clínico-nutricional, de modo que respeite a sua história de vida e leve em consideração as diretrizes nutricionais e o contexto em que ambos (nutricionista e paciente) se encontram na elaboração do aconselhamento dietético. Esse encontro deve se pautar ainda por uma relação dialógica bidirecional que promova a autonomia do paciente para a coprodução do seu projeto dietoterapêutico singular. $O$ estabelecimento da competência dialógica na clínica nutricional possibilita a seus formuladores estarem presentes como sujeitos e, desse modo, não repetindo práticas, mas formulando-as conjuntamente 3,4,35,36,68. Ao fazer isso, possivelmente, esse profissional estará abrindo caminhos para maior articulação entre saberes e para a ampliação da humanização da relação paciente-nutricionista na prática clínica nutricional. Esse modo de atuar pode instigar ainda o desenvolvimento de mais estudos sobre a abordagem das bases teórico-metodológicas da nutrição clínica ampliada.

Ressalta-se que a realização do aconselhamento dietético na prática clínica, pautada pela problematização do comportamento alimentar, no diálogo e escuta em suficiência e na articulação de saberes, é possível e ao mesmo tempo impres- 
cindível, porque há necessidade de superar modelos dogmáticos, padronizados, lacônicos, baseados, sobretudo, em restrições e normas que pressupõem um comportamento heterônomo do paciente, e porque existe a possibilidade de planejamento e implementação de ações de educação nutricional em um processo comprometido com a compreensão da condição humana, considerando os valores culturais e os indivíduos como sujeitos sócio-históricos, além da possibilidade do estabelecimento de uma relação bidirecional entre educador-educando (nutricionista-paciente $)^{33,34,69,70}$. Freire ${ }^{69}$ e Morin ${ }^{70}$ respaldam essas iniciativas que propõem a contextualização dos saberes e sua integração, favorecendo a inteligência geral, a problematização além das fronteiras disciplinares e a articulação dos conhecimentos, a autonomia dos sujeitos e a democratização na relação educando-educador.

Quanto ao papel do nutricionista como educador em alimentação, nutrição e saúde, Santos ${ }^{29}$ enfatiza a sua importância na formação de opinião, condição essencial para a tomada de decisões por parte do paciente. A autora destaca ainda que "o fazer" educação nutricional deve compreender a complexidade da alimentação e os significados que os indivíduos atribuem às suas práticas alimentares. Esse processo pedagógico-nutricional encontra sustentação nas discussões e reflexões desenvolvidas em várias áreas do conhecimento, em especial nas ciências sociais e humanas, nas quais são colocadas em evidência por aqueles que estudam questões relacionadas ao fenômeno alimentar.

De certa maneira, se a nutrição clínica assumir o diálogo entre o saber técnico-científico e o saber prático e compreender a importância do saber dos pacientes na materialização da terapia nutricional singular (que transcende o individual do caso clínico para pensar na rede social e familiar que conforma o sujeito adoecido), poderá haver uma integração entre a tecnociência e a vida ou, como é colocado por Solymos ${ }^{13}$ e Ayres ${ }^{18}$, com os projetos de felicidade dos sujeitos que buscam o cuidado em saúde e nutrição.

\section{CONSIDERAÇÕ ES FINAIS}

Os pontos aqui abordados, analisados cuidadosamente, propõem ao leitor pensar que o trabalho do nutricionista clínico, suas dificuldades e impasses não significam demérito da sua atuação ao longo dessas décadas. São indubitáveis os avanços conquistados pela categoria no decorrer desse período e as contribuições conferidas à melhoria da nutrição, saúde e qualidade de vida das pessoas. Entretanto, há muito ainda a avançar. Assim, espera-se poder contribuir para a mudança do status quo e para a (re)construção de uma prática clínica nutricional, na qual a incompletude sinaliza para a necessidade de trabalhar com a alteridade e a bidirecionalidade das relações na perspectiva de um projeto interdisciplinar e humano.

Para tanto, são necessárias reformulações das práticas em nutrição e saúde no sentido de humanizá-las, de modo que as reflexões provocadas no bojo deste ensaio não representem contradição quando postas em prática pelo nutricionista diante do paciente. Essas reformulações devem abranger tanto a reelaboração pelas instituições universitárias do currículo dos cursos de nutrição e de outros cursos de saúde, de modo que resulte em menor fragmentação do conhecimento e maior interdisciplinaridade, perpassando pelo aperfeiçoamento docente, bem como dos gestores e profissionais já inseridos no setor; pela reforma dos serviços de saúde; pela melhoria das condições ocupacionais e da assistência aos profissionais de saúde; quanto a criação de espaços nesses serviços voltados para a reflexão e para a educação em nutrição e saúde dos usuários e pela possibilidade de ampliação do grau de desalienação e de transformação do trabalho em processo criativo e prazeroso.

O uso da expressão "ponto de continuação" na seção cerne deste ensaio tem o objetivo de despertar a reflexão do leitor para o fato de que a atuação do nutricionista na perspectiva da clínica nutricional ampliada não só pode representar objeto para novas formulações e estudos como também coaduna com os propósitos dos 
novos modos de fazer saúde da Política Nacional de Humanização da atenção e gestão do SUS, cuja assistência deve se pautar na ampliação do olhar para o sujeito inteiro; com o entendimento da complexidade do processo saúde-doença-cuidado; com a utilização de tecnologias como o acolhimento; com o maior diálogo na relação profissional-usuário; com a realização da escuta/ interpretação da demanda/necessidade do paciente.

À guisa de reflexões finais, este ensaio não objetiva aceitar ou rejeitar qualquer enunciado de tipo assertivo, mas sugerir ao leitor a análise da pertinência dos argumentos apresentados e de seu sentido e validade para a prática clínica nutricional na contemporaneidade. Em outras palavras, a intenção deste trabalho é colocar em relevo a importância do reconhecimento, por parte dos nutricionistas, dos elementos psicobiossocioculturais da alimentação e da comensalidade, tomando-os como base do modelo da nutrição clínica ampliada, para incitá-los a aproximar alimentação-nutrição e o processo saúde-doença em uma abordagem interdisciplinar capaz de não separar a racionalidade científica moderna do contexto humano, subjetivo, cultural, social, histórico e político.

\section{A GRADECIMENTOS}

À nutricionista clínica e professora doutora Raquel Rocha dos Santos pela leitura crítica do ensaio. Expressamos também nossos sinceros agradecimentos aos pareceristas anônimos pelas preciosas sugestões que contribuíram para melhorar a qualidade do ensaio.

\section{COLABORADORES}

F. DEMÉTRIO concebeu o ensaio, participou da revisão de literatura, da elaboração e da revisão de todas as etapas do trabalho. J.B. PAIVA participou da elaboração e da revisão do manuscrito. A.A.G. FRÓES contribuiu com a elaboração de algumas partes do texto e participou da revisão final do manuscrito. M.C.S. FREITAS revisou criticamente o ensaio e partici- pou da sua elaboração. L.A.S. SANTOS orientou e revisou criticamente o trabalho e colaborou com sua redação.

\section{REFERÊ N CIAS}

1. Caprara A, Franco ALS. A relação paciente-médico: para uma humanização da prática médica. Cad Saúde Pública. 1999; 15(3):647-54. doi: 10.1590/S 0102-311X1999000300023.

2. Caprara A, Rodrigues J. A relação assimétrica médico-paciente: repensando o vínculo terapêutico. Ciênc Saúde Coletiva. 2004; 9(1):139-46. doi: 1 0.1590/S1413-81232004000100014.

3. Campos GWS, Amaral MA. A clínica ampliada e compartilhada, a gestão democrática e redes de atenção como referenciais teórico-operacionais para a reforma do hospital. Ciênc Saúde Coletiva. 2007; 12(4):849-59. doi: 10.1590/S1413-812 32007000400007.

4. Campos GWS. Clínica e saúde coletiva compartilhadas: teoria Paidéia e reformulação ampliada do trabalho em saúde. In: Campos GWS, Minayo MCS, Akerman M, Drumond-Júnior M, Carvalho YM. Tratado de saúde coletiva. São Paulo: Hucitec; 2009. Unidade 2.

5. Ruiz-Moral R. Relación clínica: guía para aprender, enseñar e investigar. Barcelona: Sociedad Española de Medicina de Familia y Comunitária; 2004.

6. Luz MT. Natural, racional, social: razão médica e racionalidade científica moderna. Rio de Janeiro: Campus; 1988.

7. Camargo-Júnior KR. A biomedicina. Physis. 1997; 7(1):45-68.

8. Luz MT. Novos saberes e práticas em saúde coletiva: estudo sobre racionalidades médicas e atividades corporais. $3^{a}$ ed. São Paulo: Hucitec; 2007.

9. Castiel LD, Diaz CAD. A saúde persecutória: os limites da responsabilidade. Rio de Janeiro: Fiocruz; 2007.

10. Freitas MCS, Pena PGL, Fontes GAV, Silva DO, Santos LAS, Mello AO, et al. Uma leitura humanista da nutrição. In: Freitas MCS, Fontes GAV, Oliveira $\mathrm{N}$. Escritas e narrativas sobre alimentação e cultura. Salvador: EDUFBA; 2008. Unidade 11.

11. Freitas MCS, Minayo MCS, Fontes GAV. Sobre o campo da alimentação e nutrição na perspectiva das teorias compreensivas. Ciênc Saúde Coletiva. 2011; 16(1):31-8. doi: 10.1590/S1413-8123201 1000100008

12. Amorim STSP, Moreira H, Carraro TE. A formação de pediatras e nutricionistas: a dimensão humana. 
Rev Nutr. 2001; 14(3):111-8. doi: 10.1590/\$1415-5 2732001000200004

13. Solymos GMB. A centralidade da pessoa na intervenção em nutrição e saúde. Estud Av. 2006; 20(58): 111-22. doi: 10.1590/S0103-4014200600 0300013.

14. Bosi MLM. A nutrição na concepção científica moderna: em busca de um novo paradigma. Rev Nutr. 1994; 7(1):32-47.

15. Goulart BNG, Chiari BM. Humanização das práticas do profissional de saúde: contribuições para reflexão. Ciênc Saúde Coletiva. 2010; 15(1):255-68. doi: 10.1590/S1413-81232010000100031.

16. Deslandes SF, Mitre RMA. Processo comunicativo e humanização em saúde. Interface: Comunic Saúde Educ. 2009; 13(Supl. 1):641-9. doi: 10.1590/S 1414-32832009000500015.

17. Cunha GT. A construção da clínica ampliada na atenção básica. $3^{a}$ ed. São Paulo: Hucitec; 2010.

18. Ayres JRCM. O cuidado, os modos de ser (do) humano e as práticas de saúde. Saúde e Sociedade. 2004; 13(3):16-29. doi: 10.1590/S0104-1290200 4000300003.

19. Foucault M. O nascimento da medicina social. In: Foucault M. Microfísica do poder. $25^{\mathrm{a}}$ ed. Rio de Janeiro: Edições Graal; 2008. Unidade 5.

20. Foucault M. O nascimento do hospital. In: Foucault M. Microfísica do poder. $25^{a}$ ed. Rio de Janeiro: Edições Graal; 2008. Unidade 6.

21. Foucault M. O nascimento da clínica. $6^{a}$ ed. Rio de Janeiro: Forense Universitária; 2006.

22. Luz MT. Biomedicina e racionalidade científica no ensino contemporâneo na área de saúde. In: Souza NA, Pitanguy J. Saúde, corpo e sociedade. Rio de Janeiro: UFRJ; 2006. Unidade 4.

23. Onfray M. O ventre dos filósofos: crítica da razão dietética. Rio de Janeiro: Rocco; 1990.

24. Schraiber LB. Educação médica e capitalismo: um estudo das relações, educação e prática médica na ordem social capitalista. São Paulo: Hucitec; 1989.

25. Bosi MLM. A face oculta da nutrição: ciência e ideologia. Rio de Janeiro: UFRJ; 1988.

26. Freitas MCS. Educação nutricional: aspectos sócio-culturais. Rev Nutr. 1997; 10(1):45-9.

27. Freitas MCS, Pena PGL, Fontes GAV, Silva DO. Hábitos alimentares e os sentidos do comer. In: Diez-Garcia RW, Cervato-Mancuso AM. Mudanças alimentares e educação nutricional. Rio de Janeiro: Guanabara Koogan; 2011. Unidade 3.

28. Santos LAS, Silva MCM, Santos JM, Assunção MP, Portela ML, Soares MD, et al. Projeto pedagógico do programa de graduação em nutrição da Escola de Nutrição da Universidade Federal da Bahia: uma proposta em construção. Rev Nutr. 2005; 18(1): 105-17. doi: 10.1590/S1415-52732005000100 010.

29. Santos LAS. Educação alimentar e nutricional no contexto da promoção de práticas alimentares saudáveis. Rev Nutr. 2005; 18(5):681-92. doi: 10.15 90/S1415-52732005000500011.

30. Santos LAS. O corpo, o comer e a comida: um estudo sobre as práticas corporais e alimentares no mundo contemporâneo. Salvador: EDUFBA; 2008.

31. Diez-Garcia RW. A dieta hospitalar na perspectiva dos sujeitos envolvidos em sua produção e em seu planejamento. Rev Nutr. 2006; 19(2):129-44. doi: 10.1590/S1415-52732006000200001.

32. Boog MCF. O papel do enfermeiro no cuidado nutricional ao paciente hospitalizado. Rev Campineira Enf. 1999; 2(1):17-21.

33. Rodrigues EM, Soares FPTP, Boog MCF. Resgate do conceito de aconselhamento no contexto do atendimento nutricional. Rev Nutr. 2005; 18(1):119-28. doi: 10.1590/S1415-52732005000100011.

34. Rodrigues EM, Boog MCF. Problematização como estratégia de educação nutricional com adolescentes obesos. Cad Saúde Pública. 2006; 22(5): 923-31.

35. Scagliusi FB, Alvarenga M, Philippi ST. Conceituação de alimentação saudável sob a perspectiva biopsicossocial. In: Alvarenga M, Scagliusi FB, Philippi ST. Nutrição e transtornos alimentares: avaliação e tratamento. São Paulo: Manole; 2011. Unidade 3.

36. Alvarenga M, Scagliusi FB. Reflexões e orientações sobre a atuação do terapeuta nutricional em transtornos alimentares. In: Alvarenga M, Scagliusi FB, Philippi ST. Nutrição e transtornos alimentares: avaliação e tratamento. São Paulo: Manole; 2011. Unidade 19.

37. Vasconcelos FAG. O nutricionista no Brasil: uma análise histórica. Rev Nutr. 2002; 15(2):127-38. doi: 10.1590/S1415-52732002000200001.

38. Canesqui AM. Comentários sobre os estudos antropológicos da alimentação. In: Canesqui AM, Garcia RWD. Antropologia e nutrição: um diálogo possível. Rio de Janeiro: Fiocruz; 2005. Unidade 1.

39. Fischler C. Peut-on changer l'alimentation par decret? Cah Nutr Diet. 1989; 24(1):56-61.

40. Poulain JP, Proença RPC. O espaço social alimentar: um instrumento para o estudo dos modelos alimentares. Rev Nutr. 2003; 16(3):245-56. doi: 10.15 90/S1415-52732003000300002.

41. Koifman L. O modelo biomédico e a reformulação do currículo médico da Universidade Federal Flu- 
minense. Hist Ciênc Saúde: Manguinhos. 2001; 8(1):49-69.

42. Canguilhem G. O normal e o patológico. $6^{a}$ ed. Rio de Janeiro: Forense Universitária; 2007.

43. Rosen, G. Da polícia médica à medicina social. Rio de Janeiro: Graal; 1980.

44. Manço JC. Exame clínico: um ensaio a partir de Foucault. Medicina (Ribeirão Preto). 2004; 37:117-134.

45. Pagliosa FL, Da Ros MA. O relatório Flexner: para o bem e para o mal. Rev Bras Educ Med. 2008; 32(4): 492-9. doi: 10.1590/S0100-55022008000400012.

46. Favoreto CAO. A prática clínica e o desenvolvimento do cuidado integral à saúde no contexto da atenção primária. Rev APS. 2008; 11(1):100-8.

47. Boltanski L. As classes sociais e o corpo. Rio de Janeiro: Edições Graal; 1979.

48. Russo J. Do corpo-objeto ao corpo-pessoa: desnaturalização de um pressuposto médico. In: Souza NA, Pitanguy J. Saúde, corpo e sociedade. Rio de Janeiro: UFRJ; 2006. Unidade 4.

49. Brasil. Ministério da Saúde. Secretaria de Atenção à Saúde. Política Nacional de Humanização da Atenção e Gestão do SUS. Clínica ampliada e compartilhada. Brasília: MS; 2009.

50. Costa NMSC. Revisitando os estudos e eventos sobre a formação do nutricionista no Brasil. Rev Nutr. 1999; 12(1):5-19. doi: 10.1590/S1415-5273 1999000100001.

51. Motta DG, Oliveira MRM, Boog MCF. A formação universitária em nutrição. Pro-posições. 2003, 14(1):69-86.

52. Conselho Federal de Nutricionistas. Perfil da atuação profissional do nutricionista no Brasil. Brasília: CFN; 2006.

53. American Dietetic Association. Identifying patients at risk: ADA's definitions for nutrition screening and nutritional assessment. J Am Diet Assoc. 1994; 94(8):838-9.

54. Sousa AA, Proença RPC. La gestion des soins nutritionnels dans le secteur hospitalier: une étude comparative Brésil-France. Rech Soins Infirm. 2005; (83):28-33.

55. Fontes GAV. O "ser" obeso: processo, experiência e estigma. In: Freitas MCS, Fontes GAV, Oliveira N. Escritas e narrativas sobre alimentação e cultura. Salvador: EDUFBA; 2008. Unidade 10.

56. Benevides R, Passos E. Humanização na saúde: um novo modismo? Interface: Comunic Saúde Educ. 2005; 9(17):389-406.

57. Boff L. Saber cuidar. Ética do humano: compaixão pela terra. Rio de Janeiro: Vozes; 2004.
58. Pontieri MP, Bachion MM. Crenças de pacientes diabéticos acerca da terapia nutricional e sua influência na adesão ao tratamento. Ciênc Saúde Coletiva. 2010; 15(1):151-60. doi: 10.1590/\$141381232010000100021.

59. Hernádez-Ronquillo L, Téllez-Zenteno JF, Gardeñoespinosa J, González-Acevez E. Factors associated with therapy noncompliance in type-2 diabetes patients. Salud Pública de Méx. 2003, 45(3):191-7.

60. Koehnlein EA, Salado GA, Yarnada AN. Adesão à reeducação alimentar para perda de peso: determinantes, resultados e a percepção do paciente. Rev Bras Nutr Clin. 2008; 23(1):56-65.

61. Menéndez EL. Epidemiología sociocultural: propuestas y posibilidades. Región y Sociedad. 2008; 20(2):5-50.

62. Peres DS, Franco LJ, Santos MA. Comportamento alimentar em mulheres portadoras de diabetes tipo 2. Rev Saúde Pública. 2006; 40(2):310-7. doi: 10.1590/S0034-89102006000200018.

63. Demário RL, Sousa AA, Salles RK. Comida de hospital: percepções de pacientes em um hospital público com proposta de atendimento humanizado. Ciênc Saúde Coletiva. 2010; 15(Supl.1):1275-82. doi: 10.1590/S1413-81232010000700036.

64. Santos CRA. A alimentação e seu lugar na história: os tempos da memória gustativa. História: Quest Deb. 2005; (42):11-31.

65. Pedroso CGT, Sousa AA, Salles RK. Cuidado nutricional hospitalar: percepção de nutricionistas para atendimento humanizado. Ciênc Saúde Coletiva. 2011; 16(Supl.1):S1155-S62. doi: 10.1590/S1413-8 1232011000700047.

66. Golapan C. Dietetics and nutrition: impact of scientific advances and development. J Am Diet Assoc. 1997; 97(7):737-41.

67. Teixeira RR. O Acolhimento num Serviço de Saúde entendido como uma Rede de Conversações. In: Pinheiro R, Mattos R, organizadores. Construção da integralidade: cotidiano, saberes e práticas em saúde. Rio de Janeiro: UERJ; 2005. Unidade 5.

68. Satter EM. Eating competence: definition and evidence for the satter eating competence model. J Nutr Educ Behav. 2007; 39(Supl. 5):S189-S94.

69. Freire P. Pedagogia da autonomia: saberes necessários à prática educativa. $47^{\mathrm{a}}$ ed. São Paulo: Paz e Terra; 2007.

70. Morin E. Os sete saberes necessários à educação do futuro. $3^{a}$ ed. São Paulo: Cortez; 2001.

Recebido em: 4/1/2011

Versão final reapresentada em: 3/5/2011

Aprovado em:19/7/2011 